\title{
Corrigendum
}

\section{Corrigendum to "The Influence of Confidence and Social Networks on an Agent-Based Model of Stock Exchange"}

\author{
Mario A. Bertella, ${ }^{1}$ Jonathas N. Silva, ${ }^{1}$ André L. Correa, ${ }^{1}$ and Didier Sornette ${ }^{2}$ \\ ${ }^{1}$ Department of Economics, Sao Paulo State University (UNESP), Araraquara 14800-901, São Paulo, Brazil \\ ${ }^{2}$ Department of Management, Technology, and Economics, ETH Zurich, Zurich 8092, Switzerland \\ Correspondence should be addressed to Didier Sornette; dsornette@ethz.ch \\ Received 4 November 2021; Accepted 4 November 2021; Published 15 January 2022 \\ Copyright (c) 2022 Mario A. Bertella et al. This is an open access article distributed under the Creative Commons Attribution \\ License, which permits unrestricted use, distribution, and reproduction in any medium, provided the original work is \\ properly cited.
}

In the article titled "The Influence of Confidence and Social Networks on an Agent-Based Model of Stock Exchange" [1], the corresponding author should be listed as given above.

\section{References}

[1] M. A. Bertella, J. N. Silva, A. L. Correa, and D. Sornette, “The influence of confidence and social networks on an agent-based model of stock exchange," Complexity, vol. 2021, Article ID 1083640, 16 pages, 2021. 